\title{
Cavernous Carotid Artery Giant Aneurysm: Case Report and Literature Review
}

\section{Aneurisma gigante de artéria carótida cavernosa: relato de caso e revisão de literatura}

\author{
Lucas Willian Packer ${ }^{1}$ José Ricardo Vanzin ${ }^{2}$ Vinicius Menegon ${ }^{1}$ \\ ${ }^{1}$ Universidade do Planalto Catarinense, Lages, SC, Brazil \\ 2 Division of Neurosurgery, Hospital da Cidade, Passo Fundo, RS, Brazil \\ Address for correspondence Lucas Willian Packer, R. Augusto Ribeiro \\ Rosa, 399, Frei Rogério, Lages, SC, Brazil, CEP: 88508-240 \\ (e-mail: lukas_packer@hotmail.com).
}

Arq Bras Neurocir 2018;37:227-230.

Abstract
Keywords
- aneurysm
- intracranial aneurysm
- therapeutic
embolization

Resumo

\section{Palavras-Chave}

- Aneurisma

- Aneurisma Intracraniano

- Embolização Terapêutica
The giant aneurysm of the cavernous internal carotid artery is an uncommon event. In the case of giant aneurysmal formation, the patient presents with some signs or symptoms, reported or observed on physical examination, which reveal a possible mass effect with neurovascular compression of the aneurysm, or even a subarachnoid hemorrhage due to the rupture of the aneurysm. We report the case of a 69-year-old patient who was admitted to the emergency department, referred by the basic health unit (BHU) of her locality for neurosurgical evaluation after suffering a mild traumatic brain injury (TBI). The patient, who was asymptomatic, carried with her a tomographic computerized examination of the skull, performed one day after the incident, evidencing left nodular parasellar lesion involving the cavernous sinus, discovered at random. After more specific clinical, laboratory and imaging exams, she was diagnosed with a giant aneurysm of the cavernous segment of the left internal carotid artery (LICA) and was submitted to endovascular embolization for correction.

O aneurisma gigante de artéria carótida interna cavernosa é um evento incomum. Em tratando-se de formação aneurismática gigante, frequentemente o paciente apresenta-se com algum sinal ou sintoma, relatado ou observado ao exame físico, que revela eventual efeito de massa com compressão neurovascular do aneurisma, ou até hemorragia subaracnóidea por ruptura do mesmo. Relata-se o caso de uma paciente de 69 anos, que deu entrada no serviço de emergência encaminhada pela Unidade Básica de Saúde (UBS) da sua localidade para avaliação neurocirúrgica após traumatismo cranioencefálico (TCE) leve. A paciente, que estava assintomática, trazia consigo um exame tomográfico computadorizado de crânio, realizado um dia após o incidente, evidenciando lesão de aspecto nodular paraselar esquerda, envolvendo o seio cavernoso, descoberta por acaso. Após realização de exames clínicos, laboratoriais e de imagem mais específicos, foi diagnosticada com aneurisma gigante do segmento cavernoso da artéria carótida interna esquerda e submetida à embolização endovascular para correção. received

March 20, 2018

accepted

June 8,2018

published online

August 31, 2018
DOI https://doi.org/

10.1055/s-0038-1668172. ISSN 0103-5355.
Copyright $(2018$ by Thieme Revinter

Publicações Ltda, Rio de Janeiro, Brazil
License terms

(c) (1) $\ominus$ (\$) 


\section{Introduction}

Cerebral aneurysms can be classified in accordance with their morphology, size and anatomical location. ${ }^{1}$ Intracranial aneurysms are common disorders, with a reported prevalence between 1 and $5 \%$ in the adult population. ${ }^{2}$ Those which are present in the cavernous carotid artery represent $\sim 2 \%$ of the cases. ${ }^{3}$ Prevalently, the natural history of giant intracranial aneurysms is severe. More than $50 \%$ of the patients suffer a rupture of these aneurysms and the mortality is higher than $60 \%$ in 2 years. ${ }^{4}$ Therefore, there is a surgical indication for the resolution of the disorder in most of the cases, either by endovascular or direct approach.

\section{Case Report}

A 69-year-old patient, female, white, married, housewife, literate, catholic, natural from Soledade, Rio Grande do Sul, Brazil, coming from Nicolau Vergueiro, Rio Grande do Sul, Brazil, was admitted to the emergency department in July 2017, referred by the basic health unit (BHU) of her locality, reporting a fall from her own height 15 days before with a consequent mild traumatic brain injury (TBI). One day after the fall, a computed tomography (CT) scan of the skull was performed and revealed a left parasellar nodular aspect image involving the cavernous sinus, discovered at random.

The patient arrived at the emergency unit with the CT in hand, without complaints, asymptomatic. She had history of compensated depression, in treatment for 4 years; smoker on abstinence for 10 years, referring previous cigarette use (11 years/pack); denied alcoholism, allergies or other comorbidities. On physical examination, she presented a good general condition and was lucid, oriented, and communicative, with a score of 15 on Glasgow Coma Scale. She presented isochoric and photoreagent pupils and no signs of fractalization; muscle strength and sensitivity preserved in the four limbs; myotatic reflexes and examination of the cranial nerves did not present any alterations.

During hospitalization, the patient was submitted to a brain magnetic resonance imaging (MRI) exam, in which a giant aneurysmal formation of the left internal carotid artery (LICA) was observed ( - Fig. 1). Subsequently, she was submitted to an angiography of the supra-aortic vessels, supine, under general anesthesia, with local antisepsis and fields placement, performed via bilateral femoral artery puncture with a $6 \mathrm{~F}$ introducer. During the examination, the presence of the aneurysm was confirmed in the topography of the LICA in its cavernous portion, measuring $39.2 \mathrm{~mm}$ in its largest diameter (-Fig. 2). Additionally, a new aneurysmal formation in the right upper pituitary artery, of smaller size, was discovered ( - Fig. $\mathbf{3}$ ).

During the procedure, a LICA occlusion test with a balloon was performed, revealing good patency of the anterior communicating artery. However, due to the presence of a contralateral aneurysm, it was decided to preserve the artery and perform therapy with platinum springs for embolization of the aneurysm. Ten springs were used in total, and the aneurysm was excluded from the cerebral circulation ( - Fig. 4). The embolization of the right upper pituitary artery aneurysm

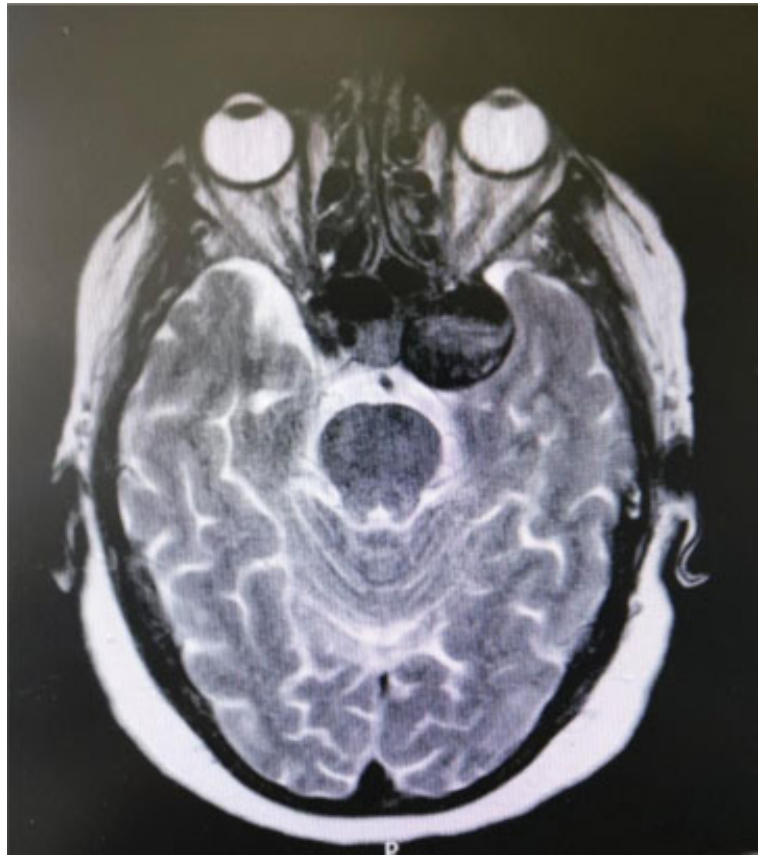

Fig. 1 Magnetic resonance imaging of the skull in axial section, weighted in T2, showing the aneurysm in the left internal carotid artery topography.

was not performed on the same day. It was decided that this procedure would be performed in a second surgery.

After the procedure, the patient was referred to the recovery room, where she woke up well, without deficits, being discharged 3 days later with a referral to the neurosurgery ambulatory to return and schedule the embolization of the remaining aneurysm.

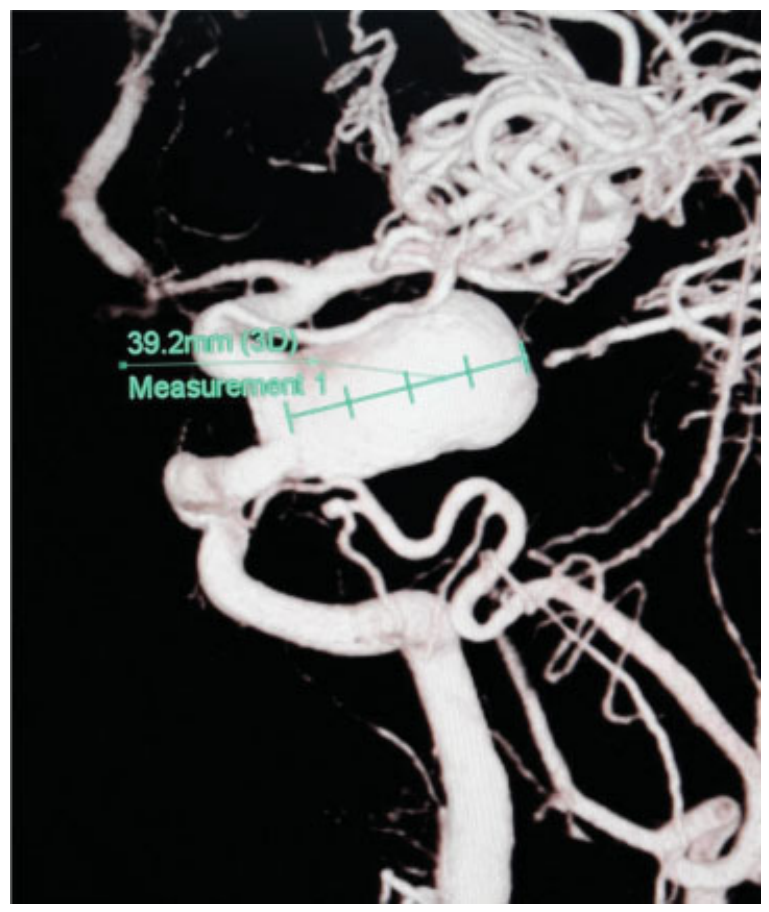

Fig. 2 Cerebral angiography with 3D reconstruction evidencing the giant aneurysm in the left cavernous carotid artery, measuring $39.2 \mathrm{~mm}$ in its largest diameter. 


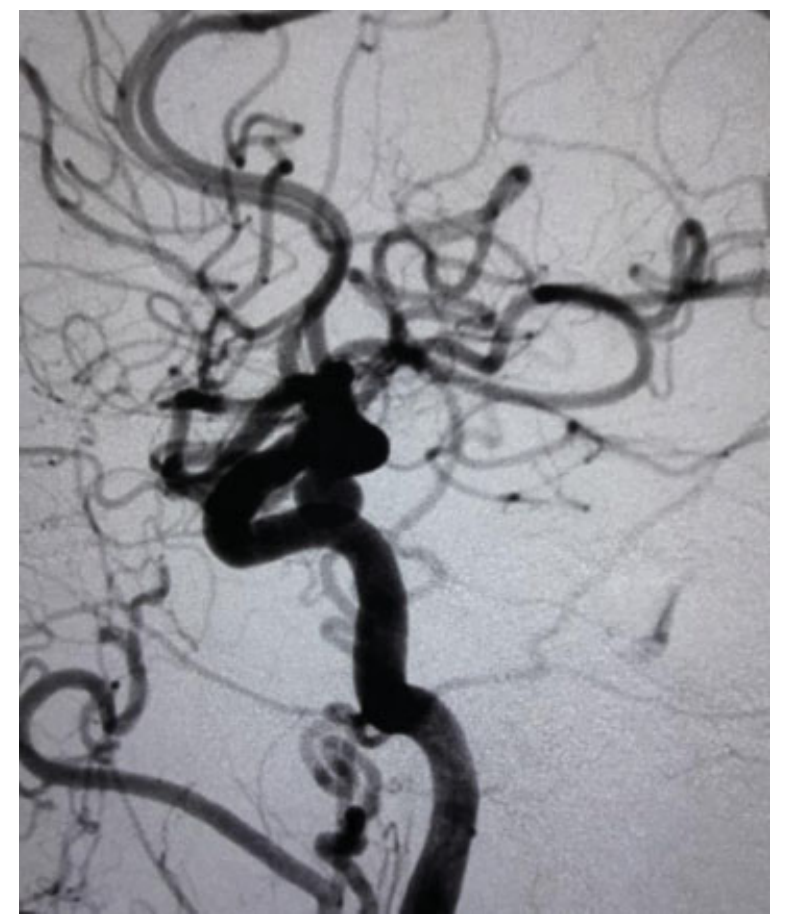

Fig. 3 Cerebral angiography evidencing the right superior pituitary artery aneurysm.

\section{Discussion}

Cavernous carotid aneurysms represent $\sim 2 \%$ of all intracranial aneurysms. ${ }^{3}$ Most aneurysms of this type are considered benign lesions, considering that $\sim 18 \%$ of the cases are asymptomatic and have a natural history with a low rate

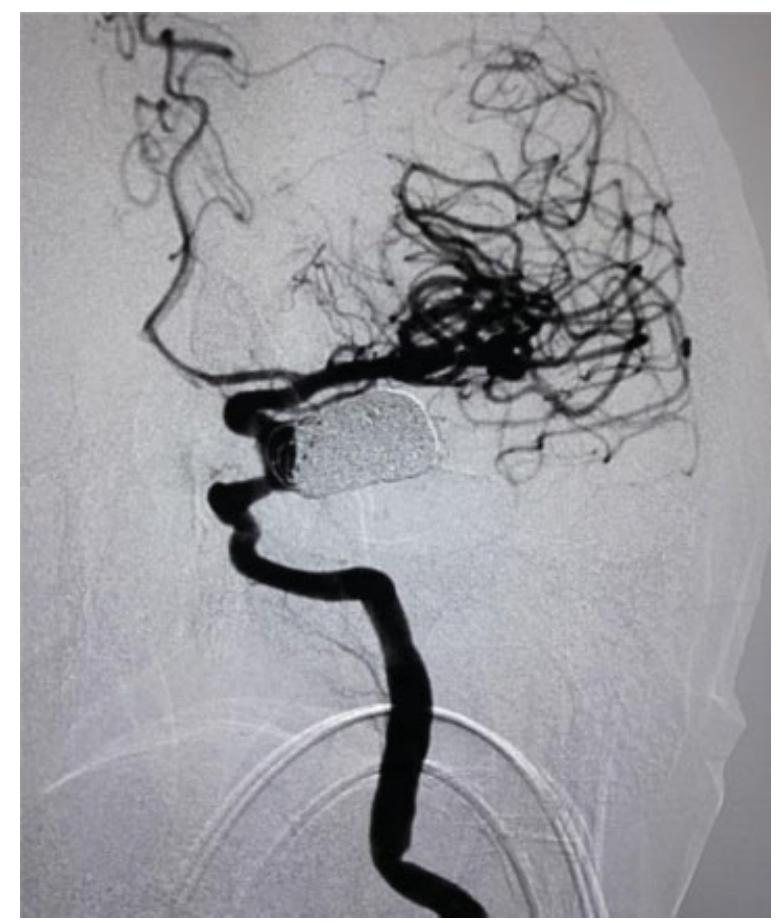

Fig. 4 Immediate control cerebral angiography evidencing the presence of the platinum springs inside the aneurysm and its exclusion from the cerebral circulation. of life-threatening complications, promoting, less frequently, symptoms by means of rupture, leading to a subarachnoid hemorrhage (SAH), severe epistaxis or even embolic events, generating a possible ischemic stroke., ${ }^{5,6}$ However, in the case of giant aneurysmal formations, intracavernous aneurysms invariably promoted symptoms as a consequence of neurovascular compression, ${ }^{6}$ which contrasts with the present case report, in which the giant aneurysm was discovered at random in an asymptomatic patient.

Cavernous aneurysms may arise from any segment of the cavernous internal carotid artery (ICA), being more commonly originated from the anterior curve extending medially. In the present case, the aneurysmal formation arose from the anterior curve of the cavernous carotid artery, horizontally, projecting sideways and subtly anterior.

Etiologically, atherosclerosis is the most common cause of aneurysms. Trauma, local inflammatory processes, and other mechanisms and associations are rarer causes of aneurysm formation. ${ }^{8,9}$ Evidence suggests the presence of hemodynamic factors in the formation and rupture of the aneurysms. The flow instability, the non-laminar turbulent flow, as well as the shear stress in the wall could contribute to endothelial damage and to the onset of aneurysm formation. Giant aneurysms generally result from the growth of small saccular aneurysms. ${ }^{10}$ The fact that the patient in the present study was a former smoker, with a previous history of 11 years smoking one pack a day, may have contributed to the formation of the aneurysm of the reported patient, suggesting a possible atherosclerotic etiology for it.

Because the patient was asymptomatic, the diagnosis occurred at random after she was submitted to a CT scan of the skull. Nevertheless, with or without symptoms, the diagnosis of the aneurysms should be made by CT, MRI and cerebral arteriography studies, the latter being more reliable. The discovery of asymptomatic and/or incidental cases has become more frequent with new non-invasive imaging diagnostic technologies. ${ }^{11,12}$

Aneurysms of the cavernous carotid artery usually have some specific indications for treatment, given the good prognosis in expectant management. Treatment is indicated in cases of intracavernous aneurysms presenting with acute rupture, progressive neurological symptoms, including compression and palsy of the cranial nerves, headache and other pain syndromes refractory to clinical treatment or, in asymptomatic patients, when the aneurysm has a diameter greater than $13 \mathrm{~mm}$ or anatomical characteristics that increase the risk of bleeding. ${ }^{13,14}$ Regarding the risk of rupture, some factors to be taken into consideration are: women have aneurysms more frequently than men, and their aneurysms have a higher risk of bleeding; the elderly population (over 60 years old) and patients with positive family history for aneurysms are also more prone to aneurysmal rupture; aneurysmal formations with a diameter $>10 \mathrm{~mm}$ have a high risk of rupture. ${ }^{15}$ Therefore, the exclusion of the cerebral circulation aneurysm was indicated in the present case because it was an elderly female patient with a giant aneurysm.

Concerning the treatment, endovascular therapy is safe and effective and, when possible, stent-assisted therapy may be the best option, with fewer complications and lower rates 
of recanalization. ${ }^{12}$ The microsurgical treatment does not represent a good option in relation to endovascular therapy due to the difficulty of surgical access for clipping and potential operative complications, such as compression of the cranial nerves and bleeding. Therefore, this therapy is reserved for cases of failure of the endovascular correction. ${ }^{14}$

A third option that proves to be effective, especially in cases of a giant aneurysm, is the occlusion of the ICA by the endovascular approach, with a good prognosis and lower recidivism rates. To assess whether the patient will tolerate carotid artery occlusive therapy, the balloon occlusion test (BTO) is performed, which consists in a temporary insufflation of a non-detachable balloon inside the ICA and monitoring the patient for a period of 20 minutes. ${ }^{16}$ During the procedure, clinical (age, neurological exam findings such as changes in cranial nerves, language, cognition, movement, and sensitivity), angiographic (presence of competent collateral circulation) and hemodynamic (cerebral blood flow, venous transit time) parameters are evaluated to determine if there is a tolerance to the test. In the case of inadequate collateral cerebral circulation, as determined by the BTO, or if the hemodynamic load due to the ICA occlusion puts other lesions at risk (for example, contralateral aneurysms or previous dissections), revascularization may be necessary before the definitive occlusive therapy. ${ }^{14,16}$

In the present case, there was a good tolerance to the BTO, with presence of adequate collateral circulation. However, due to the presence of a contralateral superior pituitary artery aneurysm, it was decided not to proceed with the occlusive therapy, opting, instead, for the embolization with springs, which proved to be an effective therapy in the immediate control image.

\section{Conclusion}

The random discovery of the giant aneurysm of the cavernous carotid artery makes the present report a peculiar case in view of the great variety of symptoms that these formations usually cause due to the neurovascular compression caused by them. Therefore, its publication was considered of interest, after a bibliographical review was performed on epidemiology, etiology, diagnosis and treatment of this condition.

\section{Conflicts of Interest}

The authors have no conflicts of interest to declare.

\section{References}

1 Pritz MB. Cerebral aneurysm classification based on angioarchitecture. J Stroke Cerebrovasc Dis 2011;20(02):162-167

2 Li Q, Lv F, Li Y, Luo T, Li K, Xie P. Evaluation of 64-section CT angiography for detection and treatment planning of intracranial aneurysms by using DSA and surgical findings. Radiology 2009; 252(03):808-815

3 Silveira RL, Gusmão S, Pinheiro N, Andrade GC. Aneurisma paraclinóideo: técnica cirúrgica e resultados em 51 pacientes. Arq Neuropsiquiatr 2004;62(2A):322-329

4 Choi IS, David C. Giant intracranial aneurysms: development, clinical presentation and treatment. Eur J Radiol 2003;46(03): 178-194

5 Stiebel-Kalish H, Kalish Y, Bar-On RH, et al. Presentation, natural history, and management of carotid cavernous aneurysms. Neurosurgery 2005;57(05):850-857, discussion 850-857

6 Vasconcellos LP, Flores JAC, Veiga JCE, Conti MLM, Shiozawa P. Presentation and treatment of carotid cavernous aneurysms. Arq Neuropsiquiatr 2008;66(2A):189-193

7 Linskey ME, Sekhar LN, Hirsch W Jr, Yonas H, Horton JA. Aneurysms of the intracavernous carotid artery: clinical presentation, radiographic features, and pathogenesis. Neurosurgery 1990;26 (01):71-79

8 Hansson GK. Inflammation, atherosclerosis, and coronary artery disease. N Engl J Med 2005;352(16):1685-1695

9 Sterpetti AV, Hunter WJ, Feldhaus RJ, et al. Inflammatory aneurysms of the abdominal aorta: incidence, pathologic, and etiologic considerations. J Vasc Surg 1989;9(05):643-649, discussion 649650

10 Bowker TJ, Watton PN, Summers PE, Byrne JV, Ventikos Y. Rest versus exercise hemodynamics for middle cerebral artery aneurysms: a computational study. AJNR Am J Neuroradiol 2010;31 (02):317-323

11 Linskey ME, Sekhar LN, Hirsch WLJr, Yonas H, Horton JA. Aneurysms of the intracavernous carotid artery: natural history and indications for treatment. Neurosurgery 1990;26(06):933-937, discussion 937 938

12 Starke RM, Chalouhi N, Ali MS, et al. Endovascular treatment of carotid cavernous aneurysms: complications, outcomes and comparison of interventional strategies. J Clin Neurosci 2014;21(01):40-46

13 ter Brugge KG. Cavernous sinus segment internal carotid artery aneurysms: whether and how to treat. AJNR Am J Neuroradiol 2012;33(02):327-328

14 Eddleman CS, Hurley MC, Bendok BR, Batjer HH. Cavernous carotid aneurysms: to treat or not to treat? Neurosurg Focus 2009;26(05):E4

15 Rinkel GJE, Djibuti M, Algra A, van Gijn J. Prevalence and risk of rupture of intracranial aneurysms: a systematic review. Stroke 1998;29(01):251-256

16 Kikuchi K, Yoshiura T, Hiwatashi A, Togao O, Yamashita K, Honda $\mathrm{H}$. Balloon test occlusion of internal carotid artery: Angiographic findings predictive of results. World J Radiol 2014;6(08):619-624 